\title{
Rancang Bangun Sistem Telemetri Pendeteksi Keberadaan Hewan Penelitian Menggunakan Sensor PIR dan Drone Berbasis Arduino Uno R3
}

\author{
Irfandi Prayogi*, Wildian \\ Jurusan Fisika FMIPA Universitas Andalas, Padang \\ Kampus Unand Limau Manis, Pauh Padang 25163 \\ *darkirfand@gmail.com
}

\begin{abstract}
ABSTRAK
Telah dirancang bangun alat pendeteksi hewan penelitian dengan sensor passive infrared (PIR), mengggunakan sistem telemetri dan dibawa oleh drone SOLO 3DR. Sistem terdiri dari tiga unit yaitu transmitter, repeater dan receiver. Unit transmitter yang terdiri dari rangkaian sensor PIR HCSR-501, buzzer dan transceiver nRF24L01+. Arduino Uno R3 digunakan sebagai pemrosesan program. Hasil deteksi hewan kemudian dikirim ke unit repeater. Unit repeater terdiri atas rangkaian transceiver nRF24L01+ yang berfungsi sebagai penguat sinyal yang akan dibawa oleh drone. Unit receiver terdiri atas rangkaian transceiver nRF24L01+ dan LCD yang berfungsi sebagai penerima dan penampil data yang dikirimkan sebelumnya. Hasil karakterisasi sensor PIR didapatkan jarak maksimum mendeteksi manusia yaitu $9 \mathrm{~m}$ dan mendeteksi kucing $80 \mathrm{~cm}$. Sistem telemetri transceiver nRF24L01+ memiliki jangkauan maksimum $900 \mathrm{~m}$ ketika tanpa penghalang dan $350 \mathrm{~m}$ ketika ada penghalang dengan kondisi cuaca cerah. Sistem drone SOLO 3DR memiliki jarak maksimum horizontal $763 \mathrm{~m}$ dan jarak maksimum vertikal $125 \mathrm{~m}$. Pengujian pengiriman data hasil deteksi hewan menggunakan telemetri nirkabel didapat hasil jarak pengiriman maksimum $500 \mathrm{~m}$ dengan ketinggian $30 \mathrm{~m}$.

Kata kunci : arduino uno R3, drone, sensor PIR, transceiver NRF24101+.
\end{abstract}

\begin{abstract}
It has been designed to build a research animal detection device with passive infrared (PIR) sensors, using a telemetry system and carried by SOLO 3DR drones. The system consists of three units, the transmitter, repeater and receiver. Transmitter unit which consists of HCSR-501 PIR sensor circuit, buzzer and nRF24L01+ transceiver. Arduino Uno R3 is used as program processing. Animal detection results are then sent to the repeater unit. The repeater unit consists of a nRF24LO1+ transceiver circuit that functions as a signal amplifier to be carried by a drone. The receiver unit consists of a nRF24LO1+ and LCD transceiver circuit that functions as the receiver and viewer of data sent previously. The results of the characterization of the PIR sensor found that the maximum distance of detecting humans was $9 \mathrm{~m}$ and detected cats $80 \mathrm{~cm}$. The nRF24LO1+ telemetry transceiver system has a maximum range of $900 \mathrm{~m}$ when without a barrier and $350 \mathrm{~m}$ when there is a barrier with sunny weather conditions. Testing of SOLO 3DR drones obtained a maximum horizontal distance of $763 \mathrm{~m}$ and a maximum vertical distance of $125 \mathrm{~m}$. Testing the delivery of animal detection data using wireless telemetry obtained the maximum sending distance of the $500 \mathrm{~m}$ repeater with a height of $30 \mathrm{~m}$.
\end{abstract}

Keywords: Arduino UNO R3, drone, PIR sensor, transceiver nRF24LO1+.

\section{PENDAHULUAN}

Penelitian biologi khususnya bidang ekologi hewan yang mempelajari tentang hubungan antara hewan dan lingkungannya seringkali dilakukan langsung dengan mencari hewan yang akan diteliti kemudian akan diamati tingkah lakunya. Hewan tersebut dipasang alat berupa GPS collar maupun radio collar yang kemudian diamati. Prinsip kerja GPS collar yaitu dengan merekam lokasi dengan bantuan GPS sehingga akan terekam daerah yang dijelajahi hewan dalam periode waktu tertentu. Daya jangkau dari GPS collar ini bervariasi mulai dari 2 $\mathrm{km}$ hingga $11 \mathrm{~km}$. Namun kekurangannya yaitu harganya yang mahal hingga puluhan juta per unitnya. Salah satu penggunaan GPS collar untuk meneliti jangkauan jelajah kawanan gajah Sumatera (Sabri dkk, 2014).

Radio collar pada prinsipnya sama dengan GPS collar, namun menggunakan gelombang radio dalam proses transmisinya dan tidak menggunakan GPS. Terdiri dari dua unit yaitu transmitter dan receiver yang akan mengirim sinyal radio jika berada dalam radius jangkauannya. Penggunaan radio collar digunakan pada penelitian mengenai aktivitas harian dan jelajah kukang Jawa (Nurcahyani, 2015). Kelemahannya yaitu daya jangkau yang pendek 
mulai dari $400 \mathrm{~m}$ hingga $2 \mathrm{~km}$. Penggunaan radio collar harus menyisir lokasi hingga sinyal dari transmitter dapat ditangkap oleh receiver membuat kurang efisien.

Seiring perkembangan teknologi saat ini memungkinkan dibuat suatu device yang digunakan untuk memudahkan pekerjaan manusia. Unmanned Aerial Vehicle (UAV) merupakan wahana udara yang mempunyai bentuk dan fungsi tergantung tujuan dibuat. Salah satu jenis UAV adalah drone. Banyak drone yang dilengkapi kamera yang berguna untuk melihat suatu keadaan yang tidak bisa dilihat langsung. Drone memiliki berbagai bentuk yang salah satunya adalah jenis quadcopter. Quadcopter yaitu jenis drone yang menggunakan empat buah baling-baling. Karena memiliki empat buah baling-baling, maka drone jenis ini lebih tahan terhadap angin dan bisa digunakan pada berbagai kondisi. Ukuran drone yang kecil membuat drone dapat dioperasikan pada medan yang tidak dapat dijangkau oleh kendaraaan lain seperti mobil.

Memanfaatkan drone dapat memonitoring daerah yang lebih luas karena beroperasi di udara sehingga tidak perlu banyak petugas untuk menyisir lokasi bencana dan ketinggian drone dapat diatur sesuai yang diinginkan. Hidayat dkk. ( 2014) mengembangkan purwarupa UAV berupa fixed wing yang digunakan untuk membantu penyelamat dalam mencari korban hilang di hutan. Drone yang dikembangkan belum memiliki sensor yang dapat mendeteksi keberadaan manusia.

Keberadaan hewan dapat dideteksi dari suhu, radiasi infrared dan berbagai parameter lainnya yang dapat digunakan. Suhu dapat diukur baik secara kontak langsung maupun tak langsung. Pengukuran langsung dilakukan dengan cara kontak langsung sensor dengan objek yang akan diukur, sedangkan pengukuran tak lansung tanpa ada kontak dengan objek. Pengukuran suhu memiliki kelemahan yaitu suhu dipengaruhi lingkungan sekitar sehingga sulit untuk mengetahui dengan pasti berapa suhu sebenarnya. Selain itu ada kamera yang dapat mendeteksi suhu lingkungan namun harganya relatif mahal. Deteksi keberadaan hewan menggunakan radiasi infrared memiliki kelebihan yaitu hewan memiliki radiasi infrared yang spesifik dan sulit dipengaruhi oleh lingkungan. Selvabala dan Ganesh (2011) mengembangkan sistem pendeteksian untuk lansia menggunakan sensor passive infrared (PIR) dan akselerometer kemudian data hasil deteksi kemudian akan dikirimkan secara telemetri dan ditampilkan melalui visual basic. Ketika lansia jatuh terdeteksi sensor, maka akan tampil notifikasi pada monitor bahwa ada lansia jatuh. Selain itu, sensor PIR juga dimanfaatkan diberbagai aplikasi sebagai sistem pengamanan. Albert (2013) mengembangkan sistem pengamanan CCTV menggunakan sensor PIR dimana jarak maksimum yang dapat dijangkau yaitu $4 \mathrm{~m}$ pada sudut $0^{\circ}$.

Yuzria (2017) mengembangkan sistem peringatan dini banjir dengan metode telemetri nirkabel dengan transceiver nRF24L01+ dimana menggunakan repeater untuk menambah jarak jangkauan pengiriman data. Thwe dan Tun (2015) mengembangkan sistem monitoring pasien yang menggunakan transceiver nRF24L01+ berbasis telemetri sehingga untuk monitoring pasien bisa dilakukan tanpa harus berada diruangan.

Berdasarkan permasalahan dan hasil penelitian sebelumnya, dalam penelitian ini telah berhasil dirancang bangun alat pendeteksi keberadaan hewan penelitian menggunakan sensor PIR yang datanya dikirim secara telemetri menggunakan drone. Prinsip dari rancang bangun ini mirip seperti radio collar, namun dengan penambahan repeater untuk memperjauh jarak jangkauannya. Dengan sistim telemetri nirkabel nRF24L01+ yang terdiri atas transmitter, repeater dan receiver dan diolah dengan mikrokontroller Arduino Uno R3. Repeater dapat mendeteksi sinyal transmitter dan mengirimkan data ke receiver dan ditampilkan melalui LCD.

\section{METODE}

\subsection{Perancangan Sistem Diagram Blok}

Diagram blok sistem terdiri dari penginderaan besaran fisis berupa intensitas radiasi infrared yang dipancarkan hewan. Keluaran modul sensor ini berupa tegangan yang diproses oleh Arduino Uno R3 dan data tersebut dikirim oleh transceiver nRF24L01+ di unit transmitter. Data diterima transceiver nRF24L01+ di unit repeater lalu di proses lagi oleh Arduino Uno R3 dan dikirimkan lagi ke unit receiver. Data tersebut lalu ditampilkan di media LCD. Diagram blok sistem ditujukkan pada Gambar 1. 
unit transmitter

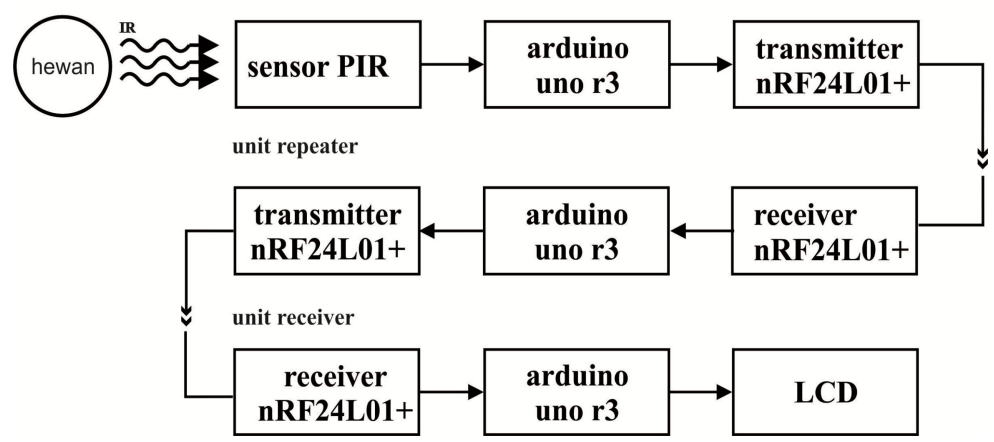

Gambar 1. Diagram blok sistem pendeteksian hewan penelitian

\subsection{Diagram Alir Perangkat Lunak Sistem}

Perancangan program menggunakan software Arduino IDE untuk menjalankan perintah yang telah diprogram. Diagram alir perancangan program ditunjukkan pada Gambar 2.

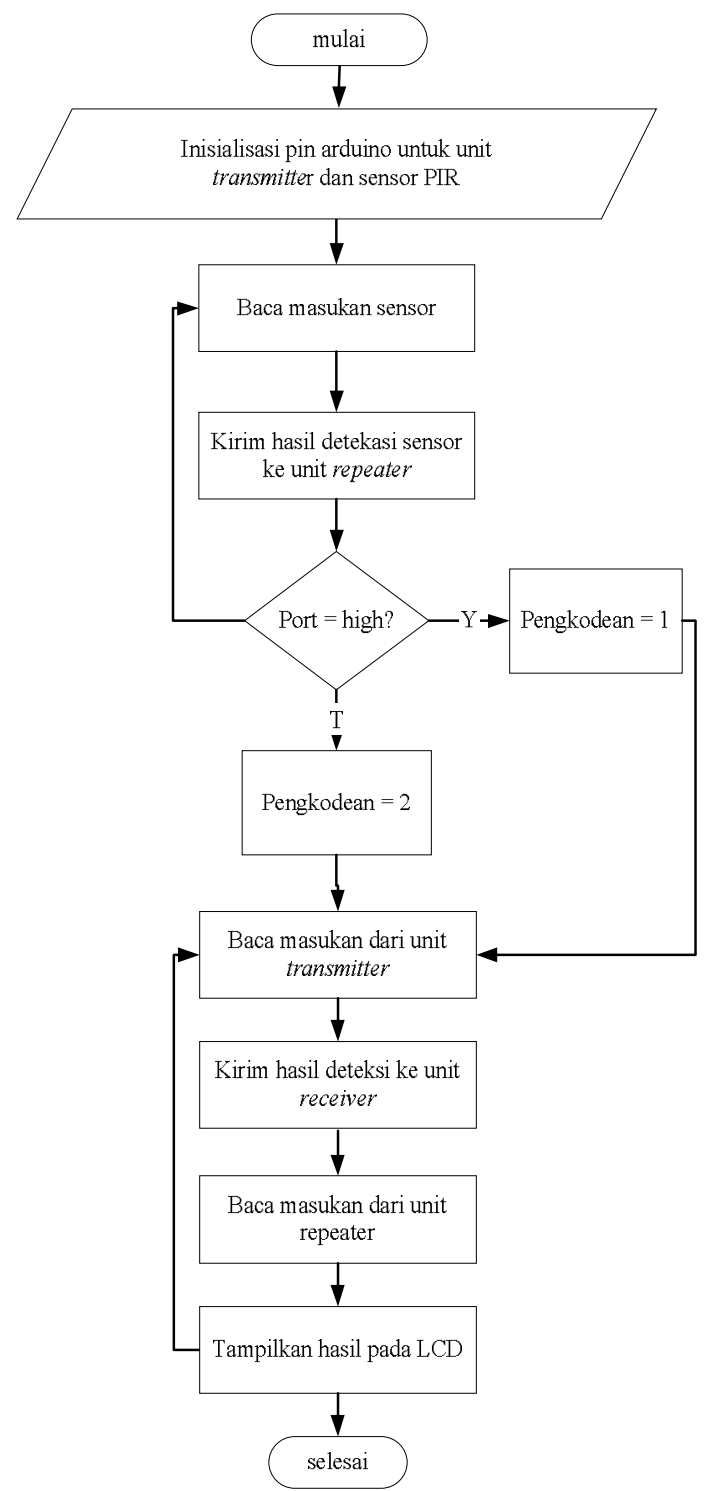

Gambar 2. Diagram alir program

Program yang akan ditulis diawali dengan inisialisasi pin mikrokontroler pada unit transmitter, repeater dan receiver. Program dibuat sesuai dengan port yang telah ditentukan 
sebelumnya sebagai masukan dan keluaran. Unit transmitter, port 2 sebagai port masukan dari sistem sensor, port 3 sebagai keluaran dari buzzer, port 9 sampai port 13 digunakan sebagai masukkan transceiver nRF24L01+, unit repeater, port 9 sampai port 13 digunakan sebagai masukkan transceiver nRF24L01+. Unit receiver terdiri dari port masukan nRF24L01+ dan port LCD. Data hasil deteksi sebagai keluaran berupa tampilan pada LCD. Sebelum dilakukan perancangan program pada PC maka perancangan program terlebih dahulu dibuat dalam sebuah diagram alir yang akan menjadikan alur pemikiran untuk pembuatan program.

\subsection{Perancangan Sistem Pendeteksi Keberadaan Hewan Penelitian}

Perancangan alat secara keseluruhan dilakukan dengan mengabungkan blok-blok rangkaian yang terdiri dari unit transmitter, unit repeater dan unit receiver. Perancangan alat dilakukan dengan menempatkan transmitter dan receiver pada jarak $700 \mathrm{~m}$. Unit repeater ditempatkan pada drone yang kemudian diterbangkan pada ketinggian $\pm 30 \mathrm{~m}$. Drone dijalankan secara horizontal dengan variasi jarak $100 \mathrm{~m}$, kemudian dilihat jarak maksimum data dapat dikirim ke unit receiver. Gambaran kerja sistem dapat dilihat pada Gambar 3.

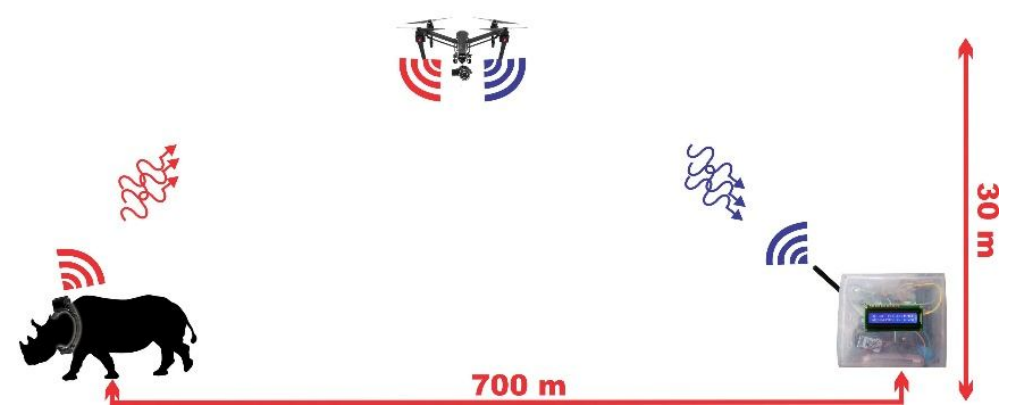

Gambar 3. Gambaran sistem kerja alat pendeteksi keberadaan hewan

\section{HASIL DAN DISKUSI}

\subsection{Hasil Karakterisasi Sensor PIR}

Karakterisasi sensor PIR HCSR-05 dilakukan untuk mengetahui kemampuan sensor dalam mendeteksi radiasi infrared yang dipancarkan Subyek. Rangkaian sensor PIR HCSR-05 ditempatkan pada bidang datar kemudian subyek bergerak dengan jarak yang telah diatur sebelumnya. Subyek uji yaitu manusia dan kucing. Data hasil karakterisasi sensor PIR dapat dilihat pada Tabel 1.

Tabel 1 Karakterisasi sensor PIR subjek manusia

\begin{tabular}{ccc}
\hline $\begin{array}{c}\text { Jarak } \\
\text { sensor- } \\
\text { objek }(\mathbf{m})\end{array}$ & $\begin{array}{c}\text { Hasil } \\
\text { deteksi } \\
\text { (Ya/Tidak) }\end{array}$ & $\begin{array}{c}\text { Buzzer } \\
\text { (Hidup/Mati) }\end{array}$ \\
\hline 1 & Ya & Hidup \\
2 & Ya & Hidup \\
3 & Ya & Hidup \\
4 & Ya & Hidup \\
5 & Ya & Hidup \\
6 & Ya & Hidup \\
7 & Ya & Hidup \\
8 & Ya & Hidup \\
9 & Ya & Hidup \\
10 & Tidak & Mati \\
\hline
\end{tabular}

Jarak manusia dengan sensor divariasikan 1 meter hingga 10 meter dan dilihat apakah sensor dapat mendeteksi objek atau tidak, sedangkan jarak kucing dengan sensor divariasikan dari jarak $10 \mathrm{~cm}$ hingga $100 \mathrm{~cm}$. Sinyal keluaran sensor berupa data digital dimana ketika mendeteksi ada radiasi akan bernilai high dan bernilai low ketika tidak mendeteksi radiasi. 
Intensitas radiasi yang dipancarkan manusia cukup jauh hingga $9 \mathrm{~m}$. Selanjutnya dilakukan pengujian terhadap subjek kucing dan didapatkan hasil pada Tabel 2.

Tabel 2 Karakterisasi sensor PIR subjek kucing

\begin{tabular}{ccc}
\hline $\begin{array}{c}\text { Jarak sensor- } \\
\text { objek (cm) }\end{array}$ & $\begin{array}{c}\text { Hasil } \\
\text { deteksi } \\
\text { (Ya/Tidak) }\end{array}$ & $\begin{array}{c}\text { Buzzer } \\
\text { (Hidup/Mati) }\end{array}$ \\
\hline 10 & Ya & Hidup \\
20 & Ya & Hidup \\
30 & Ya & Hidup \\
40 & Ya & Hidup \\
50 & Ya & Hidup \\
60 & Ya & Hidup \\
70 & Ya & Hidup \\
80 & Ya & Hidup \\
90 & Tidak & Mati \\
100 & Tidak & Mati \\
\hline
\end{tabular}

Tabel 2 menunjukkan radiasi infrared yang dipancarkan kucing mencapai jarak maksimum $80 \mathrm{~cm}$. Kedua tabel diatas menunjukkan bahwa intensitas radiasi berbeda berdasarkan jarak pancarannya, namun dalam penggunaan alat sebagai pendeteksi hewan tidak dipengaruhi jarak karena sensor menempel pada tubuh hewan tersebut berupa kalung (collar).

\subsection{Karakterisasi Transceiver nRF24L01+}

Karakterisasi transceiver nRF24L01+ dilakukan untuk menguji seberapa jauh jangkauan pengiriman data. Transceiver nRF24L01+ terdiri dari unit transceiver, unit repeater, unit receiver. Rangkaian arduino UNO R3 dengan transceiver nRF24L01+ yang programnya telah di upload dihubungkan dengan baterai. Pengujian dilakukan pada cuaca cerah dan dilakukan variasi ada penghalang serta tanpa penghalang. Pengukuran jarak menggunakan google map. Tabel hasil pengujian karakterisasi nRF24L01+ dapat dilihat pada Tabel 3.

Tabel 3. Hasil karakterisasi transceiver nRF24L01+

\begin{tabular}{|c|c|c|c|c|}
\hline \multirow[b]{2}{*}{$\begin{array}{l}\text { Kondisi } \\
\text { lapangan }\end{array}$} & \multicolumn{3}{|c|}{ kode pengiriman data } & \multirow[b]{2}{*}{$\begin{array}{c}\text { Jarak } \\
\text { maksimum } \\
\text { pengiriman } \\
\text { data }(\mathbf{m})\end{array}$} \\
\hline & $\begin{array}{c}\text { Unit } \\
\text { transmitter }\end{array}$ & Unit repeater & Unit receiver & \\
\hline $\begin{array}{c}\text { Cuaca cerah, } \\
\text { tanpa } \\
\text { penghalang }\end{array}$ & $\begin{array}{l}\text { tes } \\
\text { jarak } \\
\text { NRF }\end{array}$ & - & $\begin{array}{l}\text { tes } \\
\text { jarak } \\
\text { NRF }\end{array}$ & 900 \\
\hline $\begin{array}{l}\text { Cuaca cerah, } \\
\text { ada penghalang }\end{array}$ & $\begin{array}{l}\text { tes } \\
\text { jarak } \\
\text { NRF }\end{array}$ & - & $\begin{array}{l}\text { tes } \\
\text { jarak } \\
\text { NRF }\end{array}$ & 350 \\
\hline $\begin{array}{c}\text { Cuaca cerah, } \\
\text { tanpa } \\
\text { penghalang }\end{array}$ & $\begin{array}{l}\text { tes } \\
\text { jarak } \\
\text { NRF }\end{array}$ & $\begin{array}{l}\text { tes } \\
\text { jarak } \\
\text { NRF }\end{array}$ & $\begin{array}{l}\text { tes } \\
\text { jarak } \\
\text { NRF }\end{array}$ & 2000 \\
\hline $\begin{array}{l}\text { Cuaca cerah, } \\
\text { ada penghalang }\end{array}$ & $\begin{array}{l}\text { tes } \\
\text { jarak } \\
\text { NRF }\end{array}$ & $\begin{array}{l}\text { tes } \\
\text { jarak } \\
\text { NRF }\end{array}$ & $\begin{array}{c}\text { tes } \\
\text { jarak } \\
\text { NRF }\end{array}$ & 800 \\
\hline
\end{tabular}

Jarak maksimum yang didapat pada pengujian transceiver nRF24L01+ adalah sejauh $900 \mathrm{~m}$ tanpa penghalang. Data ini tidak sesuai dengan datasheet karena jarak jangkauan maksimum yaitu $1 \mathrm{~km}$. Hal ini terjadi karena sumber daya yang digunakan yaitu baterai $9 \mathrm{~V}$ yang sudah sering digunakan sehingga tegangannya berkurang, akibatnya kemampuan 
mengirim data jadi berkurang. Ketika pengujian dilakukan dengan penghalang berupa pepohonan rindang didapatkan hasi jarak maksimum jangkauan $350 \mathrm{~m}$. Hal ini dikarenakan gelombang akan mengalami penyerapan (absorption), pemantulan (reflection), dan hamburan (scattering) ketika ada penghalang berupa pepohonan lebat. Sedangkan jarak maksimum menggunakan repeater mencapai $2 \mathrm{~km}$ tanpa penghalang, dan $800 \mathrm{~m}$ menggunakan penghalang.

\subsection{Pengujian Drone SOLO 3DR}

Pengujian drone dilakukan untuk mengetahui jarak dan ketinggian maksimum drone yang dapat dikontrol. Pengujian dilakukan di jalan Universitas Andalas dengan cara menghidupkan drone, kemudian tunggu hingga remot drone terhubung dengan unit drone. Drone dijalankan secara horizontal dan vertikal hingga sinyal antara drone dan remot terputus dan jarak yang muncul dicatat. Dari pengujian yang dilakukan didapatkan hasil jarak maksimum horizontal drone yaitu $\pm 760 \mathrm{~m}$. Sedangkan jarak maksimum vertikal drone diperoleh yaitu 125 m. kedua data tersebut sesuai dengan datasheet (SOLO 3DR, 2018).

\subsection{Pengujian Akhir Alat Secara Keseluruhan}

Pengujian rancangan keseluruhan dilakukan untuk menguji jarak maksimal sistem dapat mengirimkan data. Uji akhir ini menggabungkan semua rangkaian-rangkaian yang terpisah sebelumnya. Transmitter yang terdapat sensor PIR dan receiver dipisahkan sejauh $700 \mathrm{~m}$, sedangkan repeater dilekatkan pada drone dan dibawa dengan ketinggian tetap. Data hasil pengujian dapat dilihat pada Tabel 4.

Tabel 4. Pengujian jarak pengiriman data keseluruhan

\begin{tabular}{cccccc}
\hline No & $\begin{array}{c}\text { Jarak Trans- } \\
\text { rec }(\mathbf{m})\end{array}$ & $\begin{array}{c}\text { Ketinggian drone } \\
(\mathbf{m})\end{array}$ & $\begin{array}{c}\text { Jarak rec-rep } \\
(\mathbf{m})\end{array}$ & $\begin{array}{c}\text { Jarak trans- } \\
\text { rep }(\mathbf{m})\end{array}$ & $\begin{array}{c}\text { Pengiriman data } \\
\text { trans-rep-rec } \\
\text { (ya/tidak) }\end{array}$ \\
\hline 1 & & 0 & 700 & Tidak \\
2 & & 100 & 600 & Ya \\
3 & & 200 & 500 & Ya \\
4 & \multirow{2}{*}{30} & & 300 & 400 & Ya \\
5 & & 400 & 300 & Ya \\
6 & & 500 & 200 & Ya \\
7 & & 600 & 100 & Ya \\
8 & & 700 & 0 & Tidak \\
\hline
\end{tabular}

Dari Tabel 4 dapat dilihat bahwa pengiriman data ketika jarak antara receiver dan repeater $0 \mathrm{~m}$ tidak ada pengiriman data karena jarak dengan transmitter sejauh $700 \mathrm{~m}$, sedangkan dalam karakterisasi nRF24L01+ jarak maksimum ada penghalang yaitu $350 \mathrm{~m}$. Kemudian drone dimajukan bertahap dengan jarak $100 \mathrm{~m}$ dan diperoleh hasil data berhasil dikirim hingga jarak $500 \mathrm{~m}$. Namun pada jarak $0 \mathrm{~m}$ dan $700 \mathrm{~m}$ data tidak berhasil dikirim. Hal ini bisa disebabkan oleh berbagai hal seperti penghalang berupa pepohonan yang menyebabkan sinyal menjadi diserap, dipantulkan, maupun dihamburkan. Selain itu juga bisa disebabkan karena drone yang membawa repeater bergerak sehingga sinyal yang diterima bisa terganggu.

\section{KESIMPULAN}

Rancang bangun alat pendeteksi hewan penelitian menggunakan sensor PIR dengan sistem telemetri nRF24L01+ dan dibawa oleh drone SOLO 3DR telah berhasil dilakukan. Sistem terdiri dari 3 unit, yaitu unit transmitter, repeater dan receiver. Unit transmitter sebagai tempat untuk mendeteksi hewan dan mengirimkan data ke unit repeater. Unit repeater digunakan sebagai penguat sinyal sehingga dapat dikirim lebih jauh. Unit receiver sebagai tempat menerima data hasil pendeteksian sensor. Sistem telemetri nirkabel menggunakan transceiver nRF24L01+ berhasil mengirimkan data tanpa penghalang sejauh 900 m. Jangkauan maksimum ketika ada penghalang yaitu $350 \mathrm{~m}$ dengan cuaca cerah. Drone SOLO 3DR berhasil dioperasikan dengan jarak maksimum horizontal yaitu $\pm 760 \mathrm{~m}$, sedangkan jarak maksimum vertikal yaitu $125 \mathrm{~m}$. data ini sesuai dengan datasheet drone. Rancang bangun pendeteksi hewan 
dengan sistem telemetri nRF24L01+ menggunakan drone SOLO 3DR mampu mengirim data hingga $500 \mathrm{~m}$ dengan penghalang.

\section{DAFTAR PUSTAKA}

Albert, E., 2013, Sistem Otomatisasi Perekaman Video dengan Kamera CMOS 12 LED Berbasis Mikrokontroller AT89S51 Menggunakan Sensor PIR (Passive Infrared), JFU 2(1).

Hidayat,A.H., Faikar, R., Wijaya, A.P., Saripudin, A., dan Sumardi, 2014, Purwarupa Unmanned Aerial Vehicle (UAV) Sebagai Alat Bantu Tim Penyelamat Dalam Pencarian Korban Hilang Di Hutan,TRANSMISI 16(3) 155-159.

Nurcahyani, A., 2015, Aktivitas Harian Dan Wilayah Jelajah Kukang Jawa (Nycticebus Javanicus Geoffroy 1812) Di Taman Nasional Gunung Halimun Salak, Skripsi, fakultas Kehutanan, Institut Pertanian Bogor, Bogor.

Sabri, E.T.B., Gunawan,H., dan Khairijon, 2014, Pola Pergerakan dan Wilayah Jelajah Gajah Sumatra (elephas maximus sumatranus) dengan Menggunakan GPS Radio Collar di Sebelah Utara Taman Nasional Tesso Nilo, Riau, JOM FMIPA 1(2) 599-606.

Selvabala, V.S.N. dan Ganesh, A.B., 2011, Implementation of Wireless Network Sensor Base Human Fall Detection System, ICCTSD, 30(2012):767-773.

Thwe, H.M, Tun, H.M. 2015,Patien Health Monitoring Using Wireless Body Area Network, I.J.S.T. 4(6): 364-368.

Yuzria, H.,2017, Rancang Bangung Sistem Peringatan Dini Banjir Menggunakan Metode Telemetri Nirkabel Dengan Transceiver nRF24l01+, Tesis, Jurusan Fisika, Universitas Andalas, Padang. 